\title{
The Relationship Between Cerebral Blood Flow and the EEG in Normals
}

\author{
DEVIDAS MENON, ZOLTAN KOLES and ALLEN DOBBS
}

SUMMARY: Using the Xel33 inhalation technique, measurements of the blood flow to the left and right parietal and temporal regions of the cerebrum were obtained in 5 healthy individuals while simultaneously recording their EEGs. Up to 3 measurements were obtained from each of the subjects the first while they were mentally at rest and the others while they were engaged in prescribed forms of mental activity. Relationships between the measured blood flow through grey matter. initial slope index, relative grey weight, percent grey flow and power in the delta.

RÉSUME: Nous avons mesuré le flot sanguin aux régions pariétales et temporales droites et gauches, à l'aide de la technique à l'inhalation du Xe133, chez 5 individus normaux tout en enrigistrant simultanément leurs EEG. 3 enregistrements furent obtenus de chacun des sujets, le premier lors du repos mental et les autres en soutenant une activité mentale prescrite. Nous avons examiné les interrelations entre les paramètres suivants: flot sanguin mesuré à la matière grise, index de la pente initiale, poids relatif de la matière grise, delta-theta, alpha, beta and gamma rhythms of the EEG were examined. The results showed that for the subject group as $a$ whole there was a strong correlation between the power present in the low frequency components of EEG and the grey flow and relative grey weight parameters of bloodflow. On an individual basis, the observed relationships were highly variable particularly at high flow' rates and at low relative grev weights, but became much more definitive at low flow's and high weights. The results as they relate to previous work of this kind are discussed.

pourcentage de flot dans matière grise et puissance des rythmes delta, delta-theta. alpha, beta et gamma. Les résultats pour le groupe en son entier indiquent une forte correlation entre la puissance des composantes à faible fréquence de l'EEG, le flot dans sa matière grise et le poids relarif de la matière grise. Sur le plan individuel ces correlations étaient très variables, surtout à des taux élevés de flot et des poids bas de matière grise. A flots bas et poids élevés les corrélations étaient plus évidentes.
From the Division of Biomedical Engineering, and Applied Sciences, and the Department of Psychology. The University of Alberta, Edmonton, Alberta, Canada.

Reprint requests to: Dr. D. Menon, 10-102 Clinical Sciences Building, University of Alberta, Edmonton, Alberta, Canada T6G 2G3

\section{INTRODUCTION}

Two measures of human cerebral function are regional cerebral blood flow (rCBF) and the EEG. rCBF has been measured in various patient groups (Hachinski et al., 1977; Weir et al., 1978; Enevoldsen and Jensen, 1978; Menon and Weir, 1979; York et al., 1979) and has been demonstrated to be clinically useful. Computerised frequency spectrum analysis of the EEG waveform has become more widely accepted as a reliable technique. The relationship between EEG spectral parameters and mental activity has been important in the formulation of cerebral dominance and hemispheric lateralisation (Butler and Glass, 1976; Shaw et al., 1977, Galen et al., 1978).

Relatively few studies have been undertaken in which both rCBF and EEG were measured. A number of these were conducted on experimental animals (Ingvar, 1977; Baldy-Moulinier, 1975; Grossman et al., 1975). Of the human studies (Obrist et al., 1963; Trojaborg and Boysen, 1973; Ingvar et al., 1965; Sulg and Ingvar, 1968), all but one employed invasive techniques for rCBF determination, and, in some cases, measurement was not simultaneous. We are aware of only one published investigation describing noninvasive rCBF measurement simultaneously with spectrally analysed EEG. (Baron et al., 1979). In this case, there was no strong correlation demonstrated between $\mathrm{rCBF}$ and any special components of the EEG.

\section{METHODS}

A total of 14 simultaneous $\mathrm{rCBF} / \mathrm{EEG}$ measurements were made on 5 healthy righthanded normals aged $23-41$ years. Up to 3 measurements were made on each of the subjects. At the first session the subject was relaxed and mentally at rest trying to think of nothing in particular. The second session involved the subject in a vocabulary 
exercise while the third required the matching of various patterns and shapes. It was expected that these three kinds of mental activity would have a significant effect upon the relative proportion of the various rhythms present in the EEG. Therefore, these might well be reflected by correlated changed in $\mathrm{rCBF}$.

Regional cerebral blood flow was measured using a 16-channel Xe 133 inhalation system manufactured by Medimatic Inc. Twelve of the 16 available probes (3/4" $\mathrm{x} \mathrm{3/4"} \mathrm{NaI(Tl)} \mathrm{scintillation} \mathrm{detectors)}$ were utilized for this study. Groups of three detectors were placed over the parietal $(P)$ and temporal $(T)$ regions of each hemisphere ( $R$ and $L$ ). Flow parameters cited for each of these four regions (RP, RT, LP and LT) were the means of those obtained from each of the three detectors. Four parameters were calculated for each region; these were:

(i) Fg: flow through grey matter (grey flow), in $\mathrm{ml} / 100 \mathrm{~g}$ of tissue/minute;

(ii) ISl: Initial slope index, based on the second to third minute of washout;

(iii) $\mathrm{Wg}$ : relative weight of grey matter, and

(iv) FF l: the contribution of grey flow to total flow.

Normal values for these parameters have been documented elsewhere.

The EEGs were recorded using surface electrodes placed at locations $P_{4}, T_{4}, P_{3}$, and $T_{3}$ of the International 10-20 system with reference to $C_{2}$ on the midline. Attachment of the electrodes was such that the impedance measured between each electrode and the combination of the other four was less than 2 kilohms. Amplification of the scalp potentials was obtained by using a Grass Instruments Model 5 Electroencephalograph with frequency limits set at 1 and $50 \mathrm{~Hz}$. The level of amplification in the passband was fixed at near 30,000. Amplification at this level seemed to provide good resolution at the \pm 2.5 volt input range of the data acquisition system.

The data acquisition and analysis system consisted of a Hewlett Packard 2100S Computer, 5610A Analog-to-Digital Converter and various associated peripheral devices. The EEGs from the four electrodes, referenced as described, were each sampled at the rate of 120 per second and stored on a magnetic tape. Recording sessions were simultaneous with the blood-flow measurements and lasted about 10 minutes. The analysis of the stored data was completed off line.

The analysis of each 10 minute recording consisted of dividing the collected data from each electrode into segments containing 256 consecutive samples and calculating the discrete Fourier transform of each. The average power spectrum for each electrode location was obtained by averaging the contributions from all of the segments in the recording. This method for the calculation of the power spectrum is based upon that suggested by Welch (1967). To obtain a measure of the mean-squared value (average power) of the various rhythms present in the EEG at each electrode location, the coefficients of the power spectrum falling within the respective bands were averaged. For example, alpha power consisted of the average of the 19th to the 28th spectral coefficients. In all, mean-squared values were calculated for the delta, delta-theta, alpha, beta and gamma rhythms.

\section{RESULTS}

Figures 1 and 2 show the relationships obtained between grey flow and alpha power from the four regions of the brain indicated. Linear correlation coefficients calculated for each case ranged from .53 between flow and left parietal alpha power to .70 between flow and left temporal alpha power. A statistical assessment of these results indicates that although the dependence between blood flow and alpha power cannot be termed strong, even the

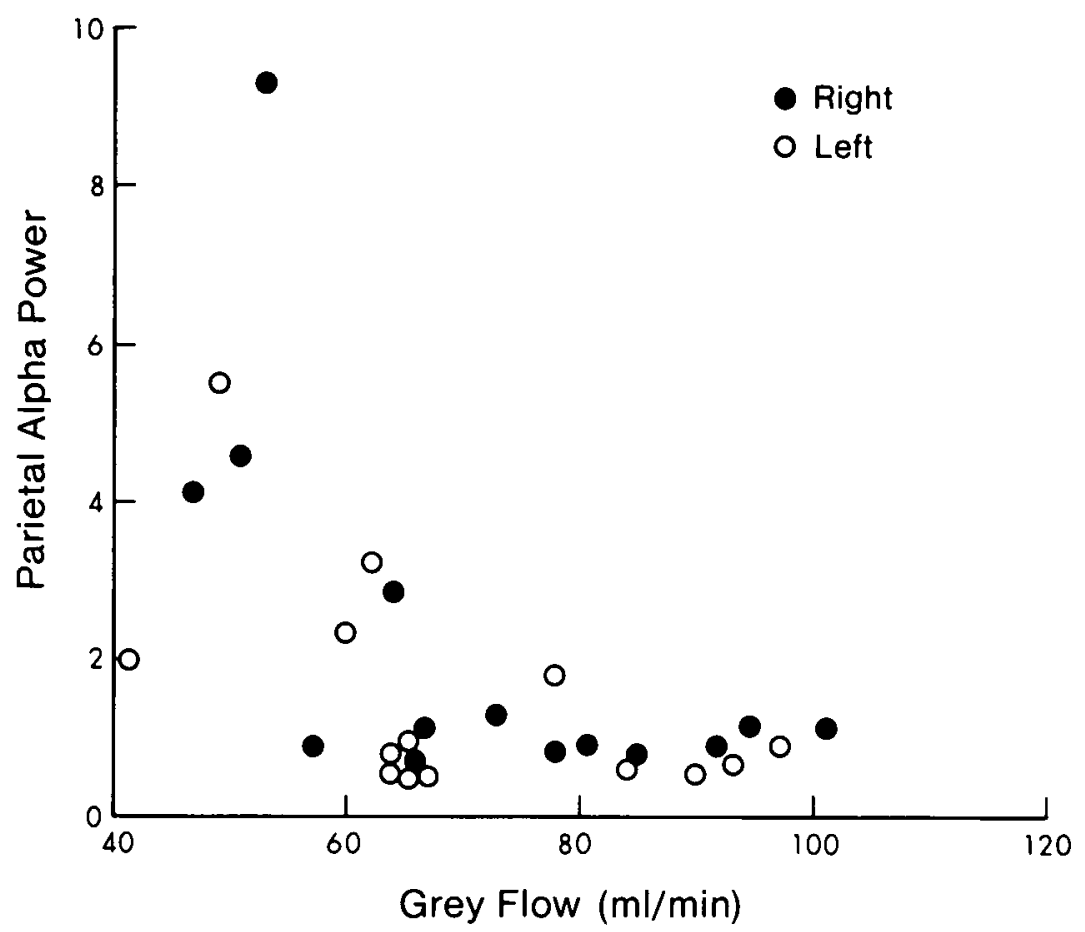

Figure $I$ - The relationship obtained between parietal alpha power $(8-13 \mathrm{c} / \mathrm{sec})$ in arbitrary units to blood flow through $100 \mathrm{~g}$ of grey matter. Linear correlation coefficients calculated between these variables were .53 for the left side and .60 for the right side. These values are significant at the $97.5 \%$ level of confidence. Linear correlation coefficients calculated for exponentially transformed data were only slightly larger than those above. 


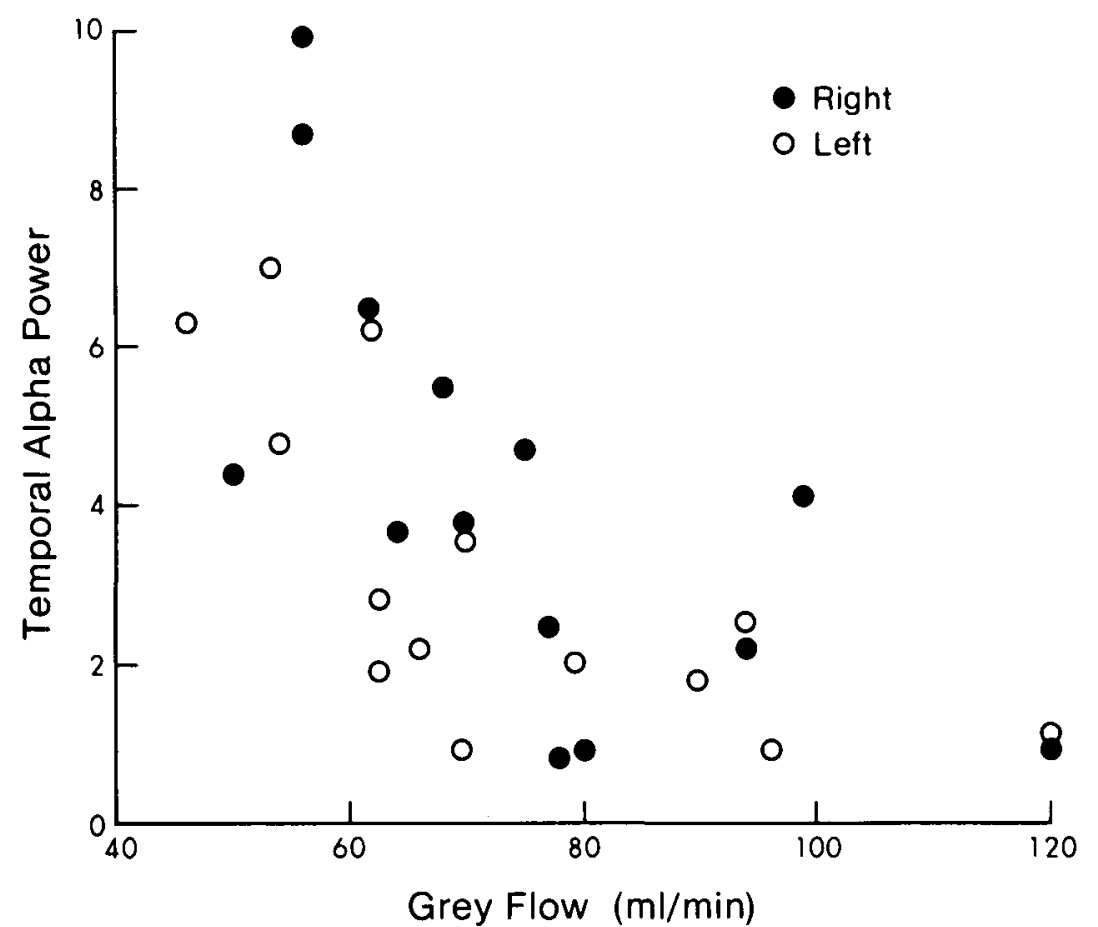

Figure 2 - The relationship obtained between temporal alpha power $(8-13 \mathrm{c} / \mathrm{sec})$ in arbitrary units to blood flow through $100 \mathrm{~g}$ of grey matter. Linear correlation coefficients calculated between these variables were .70 for the left side and .66 for the right side. These values are significant at the $99.5 \%$ level of confidence. Linear correlation coefficients calculated for exponentially transformed data were only slightly larger than those above.

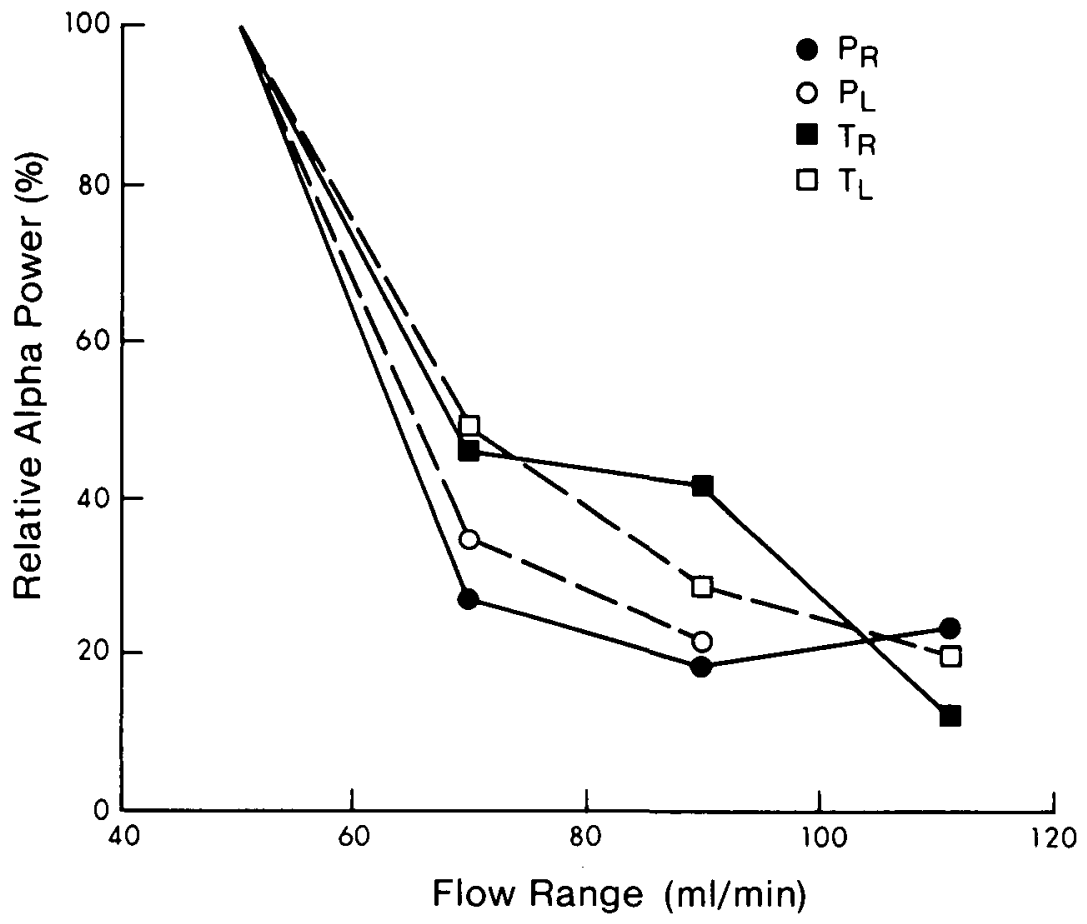

Figure 3 - The average alpha-band power in the EEG obtained from the subject group in each of four flow ranges. Flow ranges used were 40-60, 60-80, 80-100 and 100-120 $\mathrm{ml} / \mathrm{min}$ through $100 \mathrm{~g}$ of grey matter. Points were normalized to a value of $100 \%$ in the $40-60 \mathrm{ml} / \mathrm{min}$ flow range. to those in figure 3. Similar tabulations were also compiled for the RP, LP and LT regions with similar results in all cases. In general, there appears to be no correlation between FFI or ISI and any of the EEG rhythms measured. However, correlation between $\mathrm{Fg}$ and $\mathrm{Wg}$ and the magnitudes of the lowfrequency rhythms seems to be present. An increase in grey flow tends to be associated with a reduction in power in the delta, delta-theta and alpha bands while the opposite is true for $\mathrm{Wg}$.

\section{DISCUSSION}

Our data suggests that a relationship exists between $\mathrm{rCBF}$ and electrical activity. There is an inverse relationship between some of the EEG rhythms, viz. those below $13 \mathrm{c} / \mathrm{sec}$, and grey flow (Table I, Figure 3). Figures 1 and 2 show that on an individual basis, the results are highly variable, and that only in extreme cases of high power can a prediction of a correspondingly low flow be made with any degree of certainty. The finding of a highly variable relationship between flow and the EEG, to a large extent, corroborates those of Obrist et al (1963).

In an earlier investigation, Obrist et al (1963) found that in a group of elderly and psychiatric patients, lower flows tended to be accompanied by lower peak frequencies. In another study, Sulg and Ingvar (1968) demonstrated a significant correlation between mean flow and the mean EEG index in 6 patients with middle cerebral artery occlusion. Trojaborg and Boysen (1973) have demonstrated that even when flow fell by $30 \%$ during carotid endarterectomy, the EEG remained unchanged; it was not until the reduction was $50 \%$ or more that noticeable changes in the EEG were seen. They concluded that unless blood flow was reduced below a critical level, flow changes were not reflected by the EEG.

More recently, simultaneous $\mathrm{rCBF} /$ EEG measurements utilising spectral EEG analysis have been reported by Baron (1979). rCBF changes in 7 of 11 subjects before and after submaximal handwork were noted by the authors. Two of the 7 subjects who showed changes in rCBF also showed decreased alpha power while 2 others showed an increase. 
TABLE I

\section{AVERAGE POWER}

\section{FREQUENCY BAND}

\begin{tabular}{lrrrrrr}
\hline \multicolumn{2}{l}{ Flow Index } & delta & delta-theta & alpha & beta & gamma \\
\hline Fg: & $<60$ & 7.02 & 6.57 & 7.68 & 1.00 & 0.18 \\
& $60-79$ & 6.90 & 4.10 & 3.92 & 2.13 & 0.68 \\
& $80-99$ & 6.38 & 3.43 & 2.38 & 1.30 & 0.27 \\
& $>100$ & 2.73 & 1.65 & 0.92 & 0.62 & 0.35 \\
ISl & $<50$ & 6.88 & 5.25 & 6.08 & 1.82 & 0.57 \\
& $50-59$ & 5.55 & 2.95 & 1.62 & 1.03 & 0.30 \\
& $>60$ & 5.47 & 2.98 & 2.02 & 1.13 & 0.62 \\
Wg: & $<0.40$ & 3.70 & 2.30 & 3.43 & 1.38 & 0.68 \\
& $0.40-0.49$ & 7.02 & 3.98 & 4.35 & 1.58 & 0.38 \\
& $>0.50$ & 6.90 & 5.20 & 4.42 & 0.90 & 0.18 \\
FF $1:$ & $<65$ & 2.73 & 1.65 & 0.92 & 0.62 & 0.35 \\
& $65-74$ & 6.88 & 5.25 & 7.75 & 1.97 & 0.63 \\
& $>75$ & 6.20 & 3.57 & 2.73 & 1.23 & 0.27 \\
\hline
\end{tabular}

$\mathrm{Fg}=$ grey flow $\mathrm{ml} / 100 \mathrm{~g} / \mathrm{mn}$

$|S|=$ initial slope index

$\mathrm{Wg}=$ relative grey matter weigh

FFI = contribution of grey flow to total flow.

Table I - Average power in the various EEG rhythms as a function of flow parameter range. The values shown have been computed for the right temporal region. The various rhythms are in the following frequency bands - delta: $1-3 \mathrm{c} / \mathrm{sec}$; theta: $3-8 \mathrm{c} / \mathrm{sec}$; alpha: $8-13 \mathrm{c} / \mathrm{sec}$; beta: $13-20 \mathrm{c} / \mathrm{sec}$; gamma: $20-50 \mathrm{c} / \mathrm{sec}$.

In conclusion it is clear that the correlation between rCBF and the EEG is not strong. It has been suggested that because of the wide variability seen in the measured values of these parameters a highly correlated relationship between them is seen only in pathological states (Trojaborg and Boysen, 1973). Our results indicate that the beginning of this phenomenon is present in non-pathological states. In normals, it appears that below certain critical levels of perfusion it is possible to find consistent alterations in the EEG. In addition, in a statistical sense, there exists what appears to be a definite relationship between rCBF and the low-frequency rhythms over a wide range of flows. In other words, a relationship exists that might be considered a property of the population as a whole but is not necessarily reflected by all the individuals comprising it. Certainly, it is realistic to say that rCBF and the EEG as they are presently measured are not related strongly enough to make one or the other redundant.

\section{ACKNOWLEDGEMENTS}

The financial assistance provided for this work by the Alberta Mental Health Advisory Council and the Medical Services Research Foundation (Alberta) is gratefully acknowledged.

\section{REFERENCES}

BALDY-MOULINIER, M. (1975). Cerebral electrical activity and CBF during mental activation. In: Ingvar D. H. and Lassen N.A. (eds.), Brain Work, Munksgaard, Copenhagen pp 353-360.

BARON, J.C., ACKERMAN, R.M., CORREIA, J.A.. CHIAPPA. K.H., WOLPOW, E.R., NELSON, C.N., YOUNG, R.R., and TAVERAS, J.M. (1979). Comparison of two methods for cerebral activity: 133Xenon inhalation blood flow studies and compressed spectral analysis of EEG. Presented at: Cerebrovascular Clinical Research Centre Workshop, Phoenix.

BUTLER, S.R. and GLASS, A. (1976). EEG correlates of cerebral dominance. In: Riesen, A.H. and Thompson R.F. (eds.), Advances in Psychobiology, Vol. III, Wiley, New York pp 219-272.

ENEVOLDSEN, E.M. and JENSEN, F.T. (1978). Reproducibility of regional cerebral blood flow measurements in acute severe head injury. J. Neurosurg. 49: 366-377.

GALEN, D., JOHNSTONE, J., and HERRON, J. (1978). Effects of task difficulty on EEG measures of mental engagement. Neuropsychologia 16: 461-472.

GROSSMAN, R.G., TURNER, J.W., MILLER, J.D. and ROWAN, J.O. (1975). The relationship between cortical electrical activity, cerebral perfusion pressure and $\mathrm{CBF}$ during increased intracranial pressure. In: Langfitt, T.W., McHenry, L.C. jr., Reivich, M. and Wollman, H. (eds.), Cerebral Circulation and Metabolism, Springer-Verlag, New York.

HACHINSKI, V.C., OLESEN, J., NORRIS, J.W., LARSEN, B., ENEVOLDSEN, E. and LASSEN, N.A. (1977). Cerebral hemodynamics in migraine. Can. J. Neurol. Sci. 4: 245-249.

INGVAR, D.H., BALDY-MOULINIER, M., SULG, I. and HORMAN, S. (1965). Regional cerebral blood flow related to EEG. Acta Neurol. Scand. Suppl. 14: 179 . 182.

INGVAR, D.H. (1977). Functional responses of the human brain studied by regional cerebral blood flow techniques. Acta Clin. Belgica 32: 68-83.

MENON, D. and WEIR, B. (1979) Evaluation of cerebral blood flow in arteriovenous malformations by the Xenon 133 inhalation method. Can. J. Neurol. Sci. 6: 4II-4l6.

OBRIST, W.D., SOKOLOFF, L., LASSEN, N.A., LANE, M.H., BULLER, R.N. and FEINBERG, I. (1963). Relation of EEG to cerebral blood flow and metabolism in old age. Electroenceph. Clin. Neurophysiol. 15: 610-619.

SHAW, J.E., O'CONNOR, K.P. and ONGLEY, C. (1977). The EEG as a measure of cerebral function organisation. Brit. J. Psychiatry 130: $260-264$.

SULG, I.A., and INGVAR, D.H. (1968) Regional cerebral blood flow and EEG in occlusions of the middle cerebral artery. Scand. J. Clin. Lab. Invest. Suppl. 102: Sec. XVI:D.

TROJABORG, W. and BOYSEN, G. (1973). Relation between EEG, rCBF and internal carotid artery pressure during carotid endarterectomy. Electroenceph. Clin. Neurophysiol. 34: 61-69.

WEIR, B., MENON, D. and OVERTON, T. (1978). Regional cerebral blood flow in patients with aneurysms: Estimation by Xenon 133 inhalation. Can. J. Neurol. Sci. 5: 301-305.

WELCH, P.D. (1967). The use of the Fast Fourier Transform for the estimation of power spectra: a method based on time averaging over short modified periodograms. IEEE Trans. Audio and Electroacoustics 15: 70-73.

YORK, E.L., JONES, R.L., MENON, D. and SPROULE, B.J. (1979). Effects of secondary polycythemia on cerebral blood flow in chronic obstructive pulmonary disease. (In press) The American Review of Respiratory Disease. 